\title{
Hypoxaemia and its clinical predictors among children with pneumonia at a tertiary centre in Osogbo, Southwestern, Nigeria.
}

\author{
*Odeyemi A.O. ${ }^{1}$, Adebami, O.J. ${ }^{2}$, Okeniyi, J.A.O. ${ }^{3}$, Odeyemi, A.O. ${ }^{4}$, Kayode O.V. ${ }^{5}$
}

\begin{abstract}
Objective: Hypoxaemia is a feature of severe pneumonia particularly among children aged less than five years. This study aimed to determine the prevalence and clinical predictors of hypoxaemia among children with pneumonia.
\end{abstract}

Methods: It was a hospital-based cross-sectional observational study involving 129 children aged 1 - 59 months with both clinical and radiological pneumonia. The haemoglobin oxygen saturation $\left(\mathrm{SPO}_{2}\right)$ was obtained at presentation. Hypoxaemia was defined as $\mathrm{SPO}_{2}<90$ percent.

Result: Of the 129 subjects studied, $49(38.0 \%)$ had hypoxaemia. The clinical signs that were significantly associated with hypoxaemia were central cyanosis $(p=0.012)$, grunting $(p=0.014)$, nasal flaring $(p<$ $0.001)$, lethargy ( $<<0.001)$, restlessness ( $p=0.002)$, loss of consciousness ( $<<0.001)$, and inability to feed $(p<0.001)$. A combination of nasal flaring with central cyanosis, grunting or tachypnoea were significant predictors of hypoxaemia ( $\mathrm{p}=0.029,0.017$ and $<0.001$ respectively). Tachypnoea and nasal flaring had the highest sensitivity and specificity among the clinical signs for hypoxaemia. Prolonged hospital stay $(>$ 5 days) and mortality were significantly associated with hypoxaemia $(\mathrm{p}<0.001)$.

Conclusion: Hypoxaemia is common among children hospitalized for pneumonia. It is an important determinant of hospital stay and outcome.

Keywords: Hypoxaemia, pneumonia, hospitalized children, under-fives, clinical predictors.

*Corresponding author

Dr. Odeyemi, A.O.

ORCID -TD: httn://orcid.org/0000-0003-2934-8775

Email: abimbola.odeyemi@bowen.edu.ng

\footnotetext{
${ }^{1}$ Department of Paediatrics, College of health sciences, Bowen University, Ogbomoso, Oyo-state. Nigeria

${ }^{2}$ Department of Paediatrics and Child Health, Ladoke Akintola University of Technology, Ogbomoso, Oyo-state. Nigeria.

${ }^{3}$ Department of Paediatrics and Child Health, Obafemi Awolowo University, Ile-Ife, Osun-state. Nigeria.

${ }^{4}$ Pulmonology unit, Department of Internal medicine, College of health sciences, Bowen University, Ogbomoso, Oyo-state. Nigeria.

${ }^{5}$ Paediatrics Unit, Reddington Multi specialty Hospital, Victoria Island, Lagos-state. Nigeria
}

\footnotetext{
Research Journal of Health Sciences subscribed to terms and conditions of Open Access publication. Articles are distributed under the terms of Creative Commons Licence (CC BY-NC-ND 4.0). (http://creativecommons.org/licences/by-nc-nd/4.0).

http://dx.doi.org/10.4314/rejhs.v8i2.4
} 


\title{
Hypoxémie et ses Prédicteurs Cliniques chez les Enfants Atteints de Pneumonie dans un Centre Tertiaire à Osogbo, au Sud-Ouest du Nigéria.
}

\author{
*Odeyemi A.O. ${ }^{1}$, Adebami, O.J. ${ }^{2}$, Okeniyi, J.A.O. ${ }^{3}$, Odeyemi, A.O. ${ }^{4}$, Kayode O.V.
}

\section{Résumé}

Objectif: L'hypoxémie est une caractéristique des pneumopathies sévères chez les enfants de moins de cinq ans. Cette étude visait à déterminer la prévalence et les prédicteurs cliniques de l'hypoxémie chez les enfants atteints de pneumonie.

Méthodes: Il s'agissait d'une étude observationnelle transversale en milieu hospitalier portant sur 129 enfants âgés de 1 à 59 mois atteints de pneumonie clinique et radiologique. La saturation en oxygène de l'hémoglobine (SPO2) a été obtenue lors de la présentation. L'hypoxémie a été définie comme une SPO2 $<90 \%$.

Résultat: Sur les 129 sujets étudiés, 49 (38,0\%) souffraient d'hypoxémie. Les signes cliniques qui étaient significativement associés à l'hypoxémie étaient la cyanose centrale $(\mathrm{p}=0,012)$, les grognements $(\mathrm{p}=$ $0,014)$, le torchage nasal $(p<0,001)$, la léthargie $(p<0,001)$, l'agitation $(p=0,002)$, la perte de conscience $(\mathrm{p}<0,001)$ et incapacité à se nourrir $(\mathrm{p}<0,001)$. Une combinaison d'évasement nasal avec cyanose centrale, grognements ou ortachypnée étaient des prédicteurs significatifs d'hypoxémie $(p=0,029,0,017$ et $<0,001$ respectivement). La tachypnée et le torchage nasal présentaient la sensibilité et la spécificité les plus élevées parmi les signes cliniques d'hypoxémie. Un séjour prolongé à l'hôpital ( $>5$ jours) et la mortalité étaient significativement associés à l'hypoxémie $(\mathrm{p}<0,001)$.

Conclusion: L'hypoxémie est fréquente chez les enfants hospitalisés pour pneumonie. Il s'agit d'un déterminant important du séjour à l'hôpital et des résultats.

Mots-clés: Hypoxémie, pneumonie, enfants hospitalisés, enfants de moins de 5 ans, prédicteurs cliniques.

*Corresponding author

Dr. Odeyemi, A.O.

ORCID -ID: http://orcid.org/0000-0003-2934-8775

Email: abimbola.odeyemi@bowen.edu.ng

${ }^{1}$ Department of Paediatrics, College of health sciences, Bowen University, Ogbomoso, Oyo-state. Nigeria

${ }^{2}$ Department of Paediatrics and Child Health, Ladoke Akintola University of Technology, Ogbomoso, Oyo-state. Nigeria.

${ }^{3}$ Department of Paediatrics and Child Health, Obafemi Awolowo University, Ile-Ife, Osun-state. Nigeria.

${ }^{4}$ Pulmonology unit, Department of Internal medicine, College of health sciences, Bowen University, Ogbomoso, Oyo-state. Nigeria.

${ }^{5}$ Paediatrics Unit, Reddington Multi specialty Hospital, Victoria Island, Lagos-state. Nigeria 


\section{INTRODUCTION}

Pneumonia is the inflammation of the pulmonary alveolar spaces resulting from microorganism invasion into the lung (1). Pneumonia affects children everywhere, but is most prevalent in South Asia and sub-Saharan Africa.(2) Pneumonia is a major cause of morbidity and a leading cause of mortality in under-fives especially in developing countries $(2,3)$. About 80 percent of these deaths occur in children less than two years (4). In 2017, the World Health Organisation (WHO) estimated that pneumonia killed 808,694 children under the age of five globally, accounting for 15 percent of all deaths of children in this age group (2). Africa has the highest burden of pneumonia. In Nigeria, pneumonia accounted for about 162,000 deaths of children under the age of five in 2018 (5). Hypoxaemia is a major contributor to morbidity and mortality in childhood pneumonia (6). A prevalence rate of $31-43 \%$ of hypoxaemia has been reported among children with clinical pneumonia in a systematic review done by Lozano et al (7). In Ilorin, Nigeria, a prevalence rate as high as $41.5 \%$ has been recorded among hypoxaemic children with pneumonia (8). Hypoxaemia is particularly seen in children less than five years of age with pneumonia $(7,8)$.

Hypoxaemia is low partial arterial oxygen pressure of less than $8.0 \mathrm{kPa}(60 \mathrm{mmHg})$, this value correlates well with low peripheral haemoglobin oxygen saturation $\left(\mathrm{SPO}_{2}\right)$ less than 90 percent by pulse oximetry $(9,10)$. Hypoxaemia results from ventilation-perfusion mismatch as a result of non-ventilation of the gasexchanging units (alveoli) due to alveolar congestion with fluid or inflammatory cells that are released in response to the microorganism (10). Prolonged hypoxaemia without intervention in children with pneumonia may increase the duration of the illness, and also increase mortality $(11,12)$. This is because hypoxaemia is often associated with acidosis and organ dysfunction. The association between hypoxaemia and pneumonia suggests that its prompt detection and administration of oxygen therapy are important aspects in the management of children with pneumonia to ensure their survival. Hypoxaemia can be detected by blood gas analysis or pulse oximetry. Blood gas analysis is the gold standard for defining hypoxaemia; however, it is not widely available in resource-poor settings, it is expensive, invasive and technically demanding. Pulse oximetry is a more practical means of obtaining a continuous assessment of oxygen saturation status and allows for reliable monitoring with little or no distress to the patient (6). Pulse oximetry is an accepted standard for quick bedside detection of hypoxaemia. It has a sensitivity of $92 \%$ and specificity of $90 \%$ and its use has been validated $(6,13)$.

In a resource-poor setting where the use of pulse oximeter is limited, clinical signs may be used as a tool for detecting hypoxaemia. The inability to detect hypoxaemia early may delay the initiation of oxygen therapy, thereby resulting to a poor outcome. As earlier stated, mortality from childhood pneumonia in Nigeria is very high. Furthermore, hypoxaemia occurs frequently in childhood pneumonia and it is associated with poor outcome. Despite these, data on the occurrence of hypoxaemia among children with pneumonia in tertiary hospitals is few in southwest Nigeria. This study, therefore, aimed to determine how common hypoxaemia is in children hospitalized with pneumonia, the clinical signs that predict hypoxaemia and the association between hypoxaemia and pneumonia outcome in a tertiary centre in Osogbo, southwestern, Nigeria.

\section{MATERIALS AND METHODS}

Ethical approval for the study was obtained from the Ethics and Research Committee of Ladoke Akintola University of Technology (LAUTECH) Teaching Hospital, $\mathrm{O} \mathrm{s} \mathrm{o} \mathrm{g} \mathrm{b} \mathrm{o,} \mathrm{O} \mathrm{s} \mathrm{u} \mathrm{n} \quad \mathrm{S} \mathrm{t} \mathrm{a} \mathrm{t} \mathrm{e}$ (LTH/REC/2015/08/13/211). The study was conducted at the Children Emergency Unit (CEU) of LAUTECH Teaching Hospital Osogbo, Osun State, Nigeria. The study is a crosssectional observational study carried out over nine months (February 2017- October 2017). Children were eligible for the study if they were between the ages of 1 - 59 months with both clinical and radiologic diagnosis of pneumonia and whose caregiver gave informed consent. The diagnosis of pneumonia was made clinically when there is history of cough and/or difficult or fast breathing with or without fever $(2,14)$. Based on the clinical findings the patients were then categorised into two groups: pneumonia or severe pneumonia using the WHO guidelines (14). Children with wheeze and cough suggestive of bronchial asthma or bronchiolitis, a cough lasting more than two weeks or any feature suggestive of pulmonary tuberculosis were not included in the study. Also, those with sickle cell disease, heart murmurs or cyanosis suggestive of heart disease were excluded. Children with clinical features of severe dehydration, and/ or 
shock with poor peripheral perfusion and severe anaemia with venous haematocrit $\leq 15$ percent were excluded from the study.

\section{Sample size determination}

Since the total population of children admitted at the CEU is less than 10,000, the sample size for the study was obtained using the formula (15):

$$
\begin{aligned}
& \mathrm{nf}(\text { minimum sample size })=\mathrm{n} / 1+(\mathrm{n} / \mathrm{N}) \\
& \mathrm{n}=\frac{\mathrm{Z}^{2}}{\mathrm{PQ}}
\end{aligned}
$$

Sample size was determined to be 129 , at 95 percent confidence level using a prevalence of 10.5 percent obtained from previous study (16).

\section{Subject recruitment and data collection}

A total of 129 children who were hospitalized with both clinical and radiologic pneumonia were studied. The demographic characteristics, clinical presentation, anthropometric measurements and examination findings were documented. All the subjects were clinically evaluated at the commencement of the study. Axillary temperature, presence of pallor, central cyanosis, nasal flaring, head nodding, and altered sensorium at presentation were recorded. A child was regarded as febrile when the temperature was greater than $37.5{ }^{\circ} \mathrm{C}$ (17). Central cyanosis was defined as bluish discolouration of the tongue and buccal mucosa (17), while impaired consciousness was defined as Blantyre score < 5. (18) Significant tachypnoea was defined as respiratory rate $>60$ cycles per minute for those aged one month, $>50$ cycles per minute for those aged 2 - 11 months, and $>40$ cycles per minute for those aged 12 - 59 months (14).

The haemoglobin oxygen saturation $\left(\mathrm{SPO}_{2}\right)$ of all patients who have a clinical diagnosis of pneumonia was recorded at admission and during the period of admission. Continuous monitoring of oxygen saturation level was done for all patients with hypoxaemia and in any child who deteriorates with respiratory distress, apnoea or decreased conscious state until normal values were obtained. Thereafter, 4hourly daily monitoring was continued according to the hospital protocol as part of the vital sign measurements. The $\mathrm{SPO}_{2}$ was measured with a finger probe pulse oximeter (Onyx II $9550^{\mathrm{TM}}$ by Nonin). The index finger of the patient's right hand was used to take the $\mathrm{SPO}_{2}$ measurement. Hypoxaemia was defined as $\mathrm{SPO}_{2}$ value less than 90 percent in line with standard recommendations $(6,9)$. The $\mathrm{SPO}_{2}$ value measured at admission ( 0 hour) was used to determine the prevalence of hypoxaemia in this study. Plain chest radiographs (anteroposterior view) were obtained within 24 hours of admission after stabilising the patients. Radiologic findings were appropriately interpreted and reports were validated by a consultant radiologist (19).

\section{Statistical analysis}

This was done using Statistical Package for Social Sciences (SPSS) version 20.0 (SPSS Chicago Inc., IL, U.S.A). Means and standard deviations (SD) were determined for continuous variables. The relationship between categorical variables was determined using Chi-square test. Clinical signs that gave significant results were further analysed using a binary logistic regression model to determine the independent predictors of hypoxaemia among the children. Statistical significance was established when the value of probability "p" was less than 0.05

\section{RESULTS}

During the nine month study period, a total of 685 patients were admitted to the paediatric emergency unit, of these, 143 (20.9\%) had pneumonia. One hundred and twenty-nine children with clinical pneumonia and radiologic confirmation who met the study criteria were enrolled in the study. Of the 129 subjects, 78 $(60.5 \%)$ were males and $51(39.5 \%)$ were female, giving a male to female ratio (M: F) of 1.5: 1 . The subjects' ages ranged from 3 to 59 months with a mean \pm SD age of $21.6 \pm 16.5$ months. Median (IQR) age was 17.0 (23.0) months. Highest prevalence was among age 1 to 12 months while the least was 49-59 months.(Table 1)

\section{Oxygen saturation of subjects at admission.}

Forty-nine $(38.0 \%)$ of the 129 subjects were hypoxaemic $\left(\mathrm{SPO}_{2}<90\right.$ percent $)$ at presentation. Minimum reading was 60 percent while the maximum reading was 98 percent. The mean $\pm \mathrm{SD}$ oxygen saturation at presentation was $90.2 \pm 7.7 \%$ (Table 1$)$.

\section{Presenting symptoms in the subjects.}

Figure 1 highlights the respiratory symptoms among the subjects. These were predominantly cough, difficulty with breathing and fever. One hundred and twenty-five (96.9\%) had a cough, followed by difficulty with breathing which was reported in 115 (89.1\%) and fever in $107(82.9 \%)$. (Figure 1) 
Clinical signs elicited in the subjects.

One hundred and twenty (93.0\%) subjects had tachypnoea, $102(79.1 \%)$ had chest wall in-drawing and $101(78.3 \%)$ subjects had a fever. Tachycardia was reported in $80(62.0 \%)$ subjects. Additional signs were nasal flaring, reduced breath sounds, hepatomegaly, crepitation, grunting, and chest dullness. Cyanosis was the least common sign which was reported in seven (5.4\%) subjects. (Figure 2).

Association between hypoxaemia and the age of patients, and severity of pneumonia.

Hypoxaemia decreased with increasing age of patients. Hypoxaemia was more significant in children less than 24 months without gender difference $(\mathrm{LR} \chi 2=16.737, \mathrm{p}=$ 0.002). (Table 2)

Using the revised WHO classification of childhood pneumonia, $76(58.9 \%)$ of the subjects had pneumonia while $53(41.1 \%)$ had severe pneumonia. A greater proportion of patients with severe pneumonia were hypoxaemic at presentation compared to those with pneumonia (73.6\% versus $\left.13.2 \%, \mathrm{X}^{2}=48.40, \mathrm{p}<0.001\right)$. This is as shown in Table 2 .

Clinical predictors of hypoxaemia among children with pneumonia at presentation.

Central cyanosis $(p=0.012)$, grunting $(p=0.014)$, nasal flaring $(p<0.001)$, lethargy $(p<$ $0.001)$, restlessness $(p=0.002)$, loss of consciousness $(\mathrm{p}<0.001)$ and inability to feed $(\mathrm{p}<$ $0.001)$ were significantly associated with hypoxaemia in pneumonia. Using a combination of signs, central cyanosis and nasal flaring $(\mathrm{p}=$ $0.029)$, grunting and nasal flaring $(p=0.017)$ together with tachypnoea and nasal flaring $(\mathrm{p}<$ $0.001)$ were statistically significant.

The combination of tachypnoea and nasal flaring has sensitivity of $73.5 \%$, specificity of $62.5 \%$, $\mathrm{OR}=6.62,95 \% \mathrm{CI}=2.12-10.06$. Among the single clinical signs, nasal flaring had the highest sensitivity of $77.6 \%$, specificity of $60.0 \%$, OR= 5.18, 95\% CI=2.31- 11.60. Other signs (central cyanosis, grunting, inability to feed, loss of consciousness, and restlessness) were specific but relatively insensitive signs. (Table 3)

Following binary logistic regression model, the presence of all the statistically significant signs (either singly or combined) remained significant to the development of hypoxaemia in pneumonia ( $\mathrm{p}<0.05$ each). (Table 4)
Hypoxaemia and duration of hospital stay.

Hypoxaemia at presentation was significantly associated with prolonged duration of hospitalization of greater than five days $(66.7 \%$ versus $33.3 \%, p<0.001)$. (Table 5)

\section{Hypoxaemia and outcome of illness in the} subjects.

Thirty-six $(73.5 \%)$ of the 49 subjects who had hypoxaemia at admission were discharged home without any complication. Case fatality was $10.1 \%$ (13 out of 129 subjects). Mortality was higher in hypoxaemic than nonhypoxaemic pneumonia cases $(92.3 \%$ versus $7.7 \%$ ). (Table 5)

\section{DISCUSSION}

Pneumonia remains a leading cause of childhood morbidity globally most especially among children aged less than five years. The prevalence of hypoxaemia among hospitalized children with pneumonia at presentation was $38.0 \%$. Hypoxaemia was more frequent among those with severe pneumonia. The prevalence of hypoxaemia in this study is comparable to the range of $31-43 \%$ reported by Lozano et al in a systematic review of hypoxaemia among children with clinical pneumonia (20). The prevalence of hypoxaemia in this study is consistent with $38.7 \%$ reported by Basnet et al (21), and 39.7\% reported by Motwani et al (22) in two separate studies in India. The uniformity in findings may be explained by similar age group studied and cut off value of $\left(\mathrm{SPO}_{2}<90\right.$ percent $)$ used to define hypoxaemia.

In contrast, the prevalence observed in this present study is higher than $28.0 \%$ reported among children with acute respiratory tract infection in a cohort study done by Graham et al (23) in south-west, Nigeria. The difference in prevalence may be due to differences in the age distribution and site of study of both researches. While Graham et al (23) studied children up to 15 years, the present study involved children less than five years. Hypoxaemia has been reported to be very common in children aged less than five years $(6,8)$. Also, this present study was conducted in a tertiary hospital, while Graham et al (23) did their study in secondary level hospitals. The prevalence of hypoxaemia is generally higher in referral hospitals because more severely ill children are referred there (6).

A prevalence of $41.5 \%$ was reported by Abdulkadir et al (8), among hypoxaemic children with pneumonia in Ilorin - Nigeria. This value is slightly higher than what was reported in the 
present study. The difference in findings may be due to the significantly higher number of infants enrolled in their study. In a study conducted in India, infants have been reported to have significantly higher frequency of hypoxemia and this decrease with increasing age (21). This finding is consistent to what was observed in this present study. The reason is because infants have relative inefficient compensatory mechanisms (such as the use of accessory respiration muscles) to improve ventilation, thus making hypoxaemia worse in them (24).

Also, the prevalence of hypoxaemia reported in the present study is lower to the estimate of 59\% reported by Onyango et al (25), among Kenyan children with acute lower respiratory tract infection. A likely explanation for the observed disparity in prevalence estimates is that the present study was done at a lower altitude of 318 metres as compared to the higher altitude of 1,670 metres above sea level. The frequency of hypoxaemia is higher in high altitude region because there is a proportionate decrease in the partial pressure of oxygen as the barometric pressure decreases $(26,27)$.

In the present study, the single signs that were significantly associated with hypoxaemia were central cyanosis, grunting, nasal flaring, lethargy, restlessness, loss of consciousness and inability to feed. Using a combination of signs, the presence of central cyanosis and nasal flaring; grunting and nasal flaring; together with tachypnoea and nasal flaring had a significant association with hypoxaemia. The combination of tachypnoea and nasal flaring had a moderately high sensitivity while other combinations had low sensitivities. Central cyanosis was observed to be the most specific sign of hypoxaemia; however, it has a low sensitivity. This finding is in agreement with reports by Onyango et al (25) in Kenya and Graham et al (23) in south-western Nigeria. Cyanosis may be an insensitive sign because it is an infrequent, late, and subtle sign which may not be easily recognised in darkcomplexioned individuals (12). Cyanosis may also be unapparent in the presence of severe anaemia. Our study ensured that pneumonic children with severe anaemia were not included in order to improve identification of cyanosis when it is present. In this present study, grunting was significantly associated with hypoxaemia. This is favourably comparable with findings of Basnet (21) and Usen (12) in two previous studies in India and Gambia respectively. Both studies reported grunting as being significantly associated with hypoxaemia. Grunting is a sign of severe respiratory distress, it is a form of positive pressure ventilation employed to improve ventilation perfusion mismatch as a result of increased dead space created by lung consolidation (28). In this study, the specificity of grunting was high but sensitivity was relatively low. We observed that grunting was a predominant sign in those younger than 12 months, and uncommon in children 4years and above. Using this sign in the older child may not be sensitive in detecting hypoxaemia, it may therefore be argued to be a useful predictor of hypoxaemia only in the infants.

The present study observed that other signs such as nasal flaring, chest retractions, head nodding, inability to drink, or feed (when due to respiratory distress) and lethargy were significantly associated with hypoxaemia. This findings is consistent with previous studies $(12,21,29)$. Using a combination of signs, tachypnoea and nasal flaring had moderately high sensitivity and specificity in this study; this finding is similar to report from Sah et al (29). No single or combination of clinical signs reliably predicts hypoxaemia; this is because of the difference in predictive ability of the clinical signs. Previous researchers have also observed that the sensitivity is low for most single clinical signs, so combination of signs needs to be used in situation where pulse oximetry is not available $(6,21,22)$.

The WHO estimates an average duration of five days for the treatment of pneumonia in children (14). The duration of hospital stay exceeding five days is considered prolonged $(11,30)$. In this study, majority of those who had prolonged hospital stay had hypoxaemia $(66.7 \%$ versus $33.3 \%)$. This finding is comparable to some earlier studies $(8,11)$. Hypoxaemia results from decrease lung compliance, impaired gaseous exchange, and ventilation-perfusion mismatch. Hypoxaemia increases the need for close monitoring and supplemental oxygen therapy. These factors can be attributed to why the hypoxaemic children stay longer in the hospital. Other factors such as complications and need for a ventilator has been reported by the previous researcher as a factor for prolonged hospitalization $(11,14,30)$.

There was an increased risk of death among hypoxaemic children. This finding correlates with reports from previous studies $(8,12)$. Death may result from severe hypoxaemia due to the physiological compromise of multiple organs, such that treatment with oxygen may not avert death. 


\section{CONCLUSION}

This study concludes hypoxaemia is common in children with pneumonia requiring hospitalization, it is more prevalent in infants and it is an important determinant of hospital stay and outcome. A combination of nasal flaring and tachypnoea can be used in identifying hypoxaemia in resource poor countries where pulse oximeter may be unavailable.

Acknowledgement: We are grateful to the consultant radiologists and all the resident doctors involved in data collection and the care of the children during the period of the study. We acknowledge the assistance of all the nursing staff of the CEU unit of LAUTECH Teaching Hospital, Osogbo. We thank the parents/ caregivers of the children who participated in this study.

Conflict of interest: There are no conflicts of interest

\section{REFERENCES}

1. Aderele WI and Johnson WBR. Pneumonias. In: Azubuike JC, Nkanginieme KE. (eds.) Paediatrics and child health in a tropical region. $2^{\text {nd }}$ edition. Owerri, Nigeria: University of PortHarcourt press; 2007 p. 425-427.

2. World Health Organisation. Pneumonia Fact $\mathrm{s} \mathrm{h}$ e e t. A va i l a b l e f r o m : http://www.who.int/mediacentre/factsheets/fs33 1/en/. [Assessed $4^{\text {th }}$ April 2020].

3. Rudan I, Boschi-pinto C, Biloglav Z, Mulholland $\mathrm{K}$, Campbell H. Epidemiology and etiology of childhood pneumonia. Bull WHO 2008; 86: 408 416.

4. Walker CLF, Rudan I, Liu I, Nair H, Theodoratou E, Bhutta ZA, et al. 'Global burden of childhood pneumonia and diarrhoea', Lancet 2013;381( 9875): 1405-1416.

5. UNICEF. Nigeria contributes highest number to global pneumonia child deaths. Available from: https://www.unicef.org/. [Accessed $1^{\text {st }}$ May 2020].

6. World Health Organisation. Oxygen therapy for children. Geneva: WHO; 2016. Available from: http://apps.who.int/iris/bitstream/10665/204584 /1/9789241549554_eng.pdf. [Accessed $4^{\text {th }}$ May 2020].

7. Lozano JM. Epidemiology of hypoxaemia in children with acute lower respiratory infection. Int J Tuberc Lung Dis 2001; 5 (6): 496-504.

8. Abdulkadir MB, Ibraheem RM, Gobir AA, Johnson WBR. Hypoxaemia as a measure of disease severity in young hospitalized Nigerian children with pneumonia: A cross-sectional study. S Afr J Ch 2015; 9 (2): 53 - 56.

9. Usen $\mathrm{S}$ and Weber $\mathrm{M}$. Clinical signs of hypoxaemia in children with acute lower respiratory infection: indicators of oxygen therapy. Int J Tuberc Lung Dis 2001; 5 (6): 505 510.

10. Sarkar M, Niranjan N, Banyal Sarkar M, Niranjan $\mathrm{N}$, Banyal PK. Mechanisms of hypoxaemia. Lung India 2017; 34 (1): 47 - 60.

11. Kuti BP, Adegoke SA, Oyelami OA, Ota MO. Predictors of prolonged hospitalisation in childhood pneumonia in a rural health centre. $\mathrm{S}$ Afr J Ch 2014; 8 (1): 11 - 15.

12. Usen S, Weber M, Mulholland K, Jaffer S, Oparuago A, Adegbola R et al. Clinical predictors of hypoxaemia in Gambian children with acute lower respiratory tract infection: prospective cohort study. BMJ 1999; 318: 86 - 91.

13. Lee WW, Mayberry K, Crapo R, Jensen RL. The accuracy of pulse oximetry in the emergency department. Am J Emerg Med 2000;18(4): 427431.

14. World Health Organization. Revised WHO classification and treatment of childhood pneumonia at health facilities - Evidence $\mathrm{Sum}$ maries. Available from: http://www.who.int/maternal child adolescent/ documents/child-pneumonia-treatment/en/. [Accessed 30 $0^{\text {th }}$ April 2020]

15. Araoye MA. Subject Selection in Research Methodology with statistics for Health and Social Sciences. Ilorin, Nigeria: Nathadex Publishers; 2004 p. $115-129$.

16. Emodi IJ, Ikefuna AN, Ubesie AC, Chukwu BF, Chinawa JM. Assesment of clinical features and haematocrit levels in detection of hypoxaemia in sick children. Afr J Resp Med 2011; 7 (1): 11 - 13.

17. Swatch M. Doctor and Patient. In: Swatch M (ed.) Hutchinson's Clinical Methods. 20 ${ }^{\text {th }}$ edition. London: WB Saunders; 1995 p. 1 - 22.

18. Molyneux ME, Taylor TE, Wirima JJ, Borgstein A. Clinical features and prognostic indicators in paediatric cerebral malaria: a study of 131 comatose Malawian children. Q J Med1989; 71: 441-59.

19. Cherian T, Mulholland EK, Carlin JB, Ostensen H, Amin R, Campo M, et al. Standardized interpretation of paediatric chest radiographs for the diagnosis of pneumonia in epidemiological studies. Bull WHO 2005; 83 (5): 353 - 359.

20. Lozano JM. Epidemiology of hypoxaemia in children with acute lower respiratory infection. Int J Tuberc Lung Dis 2001; 5 (6): 496-504.

21. Basnet S, Adhikari RK, and Gurung CK. Hypoxaemia in Children with Pneumonia and Its Clinical Predictors. Indian J Pediatr 2006; 73 (9): $777-781$

22. Motwani NP, Janakiraman L, Bala SS, and Bhawnani D. Clinical Predictors of Hypoxaemia in Children with Acute Lower Respiratory Illness. Int Res J Med Sci 2015; 3 (3): 11 - 15.

23. Graham H, Bakare AA, Ayede AI, Oyewole OB, Gray A, Peel D et al. Hypoxaemia in hospitalised children and neonates: A prospective cohort study in Nigerian secondary-level hospitals. 
EClinicalMedicine 2019;16: 51-63.

24. Qureshi SA. Measurement of respiratory function: an update on gas exchange. Anaesth Intens Care Med 2011; 12: 490 - 495.

25. Onyango FE, Steinhoff MC, Wafula EM, Musia J, Wariua S, Musia J et al. Hypoxaemia in young Kenyan children with acute lower respiratory infection. BMJ 1993; 306: 612 - 615.

26. Heing NR, Pierson DJ. Mechanism of hypoxaemia. Resp Care Clin NAm 2000; 6: 501 521.

27. Grocott M, Montgomery H, and Vercueil A. Highaltitude physiology and pathophysiology: implications and relevance for intensive care medicine. Crit Care 2007; 11 (1): 203.

28. Rodriguez-Roisin R and Roca J. Update '96 on pulmonary gas exchange pathophysiology in pneumonia. Seminars in Respiratory Infections 1996;11 (1):3-12.

29. Sah HD. Study of predictors of hypoxaemia in children with Pneumonia. J Coll Med Sci Nepal 2013;9(4): 1 - 8.

30. Tiewsoh K, Lodha R, Pandey RM, Broor S, Kalaivani M, and Kabra SK. Factors determining the outcome of children hospitalized with severe pneumonia. BMC Pediatr 2009; 9:15. 
Table 1: Socio-demographic distribution and clinical characteristic of the subjects.

\begin{tabular}{lll}
\hline Socio-demographic characteristics & $\begin{array}{l}\text { Frequency } \\
(\mathbf{n}) \\
\mathbf{N}=\mathbf{1 2 9}\end{array}$ & $\begin{array}{l}\text { Percentages } \\
(\mathbf{\%})\end{array}$ \\
\cline { 2 - 3 } Age (in months) & 48 & \\
$\mathbf{1}-\mathbf{1 2}$ & 33 & 37.2 \\
$\mathbf{1 3}-\mathbf{2 4}$ & 23 & 25.6 \\
$\mathbf{2 5}-\mathbf{3 6}$ & 15 & 17.8 \\
$\mathbf{3 7}-\mathbf{4 8}$ & 10 & 11.6 \\
$\mathbf{4 9}-\mathbf{5 9}$ & & 7.8 \\
Gender & 78 & \\
Male & 51 & 60.5 \\
Female & & 39.5 \\
Haemoglobin oxygen saturation $\left(\mathbf{S P O}_{\mathbf{2}}\right)$ & \\
$\mathbf{9 0 \%}$ & 80 & 62.0 \\
$\mathbf{7 9 0 \%}$ & 49 & 38.0 \\
Severity of pneumonia & & \\
Pneumonia & 76 & 58.9 \\
Severe pneumonia & 53 & 41.1 \\
\hline
\end{tabular}

Table 2: Association between subjects' age and gender and presence or absence of hypoxaemia, and severity of pneumonia.

\begin{tabular}{|c|c|c|c|c|}
\hline Variable & $\begin{array}{l}\text { Hypoxaemia } \\
\mathrm{N}=49\end{array}$ & $\begin{array}{l}\text { Non-hypoxaemia } \\
\mathbf{N}=\mathbf{8 0}\end{array}$ & Test statistics & p-value \\
\hline \multicolumn{5}{|l|}{ Age in months } \\
\hline $1-12$ & $28(57.1)$ & $20(25.0)$ & $\mathrm{LR} \chi 2=16.737$ & 0.002 \\
\hline $13-24$ & $12(24.5)$ & $21(26.2)$ & & \\
\hline $25-36$ & $3(6.1)$ & $20(25.0)$ & & \\
\hline $37-48$ & $4(8.2)$ & $11(13.8)$ & & \\
\hline $49-59$ & $2(4.1)$ & $8(10.0)$ & & \\
\hline \multicolumn{5}{|l|}{ Gender } \\
\hline Male & $31(63.3)$ & $47(58.8)$ & $X^{2}=0.259$ & 0.611 \\
\hline Female & $18(36.7)$ & $33(41.2)$ & & \\
\hline \multicolumn{5}{|l|}{ Severity of pneumonia } \\
\hline Pneumonia & $10(13.2)$ & $66(86.8)$ & $X^{2}=48.401$ & $<0.001$ \\
\hline Severe pneumonia & $39(73.6)$ & $14(26.4)$ & & \\
\hline
\end{tabular}


Table 3: Clinical predictors of hypoxaemia at presentation among children with pneumonia.

\begin{tabular}{|c|c|c|c|c|c|c|c|}
\hline \multirow[t]{2}{*}{ Clinical Signs } & \multicolumn{2}{|c|}{ Hypoxaemia } & \multirow[t]{2}{*}{ p-value } & \multirow{2}{*}{$\begin{array}{l}\text { Sensitivity } \\
(\%)\end{array}$} & \multirow{2}{*}{$\begin{array}{l}\text { Specificity } \\
(\%)\end{array}$} & \multirow{2}{*}{$\begin{array}{l}\text { PPV } \\
(\%)\end{array}$} & \multirow{2}{*}{$\begin{array}{l}\text { NPV } \\
(\%)\end{array}$} \\
\hline & $\begin{array}{l}\text { Present } \\
\mathrm{N}=49\end{array}$ & $\begin{array}{l}\text { Absent } \\
\mathrm{N}=\mathbf{8 0}\end{array}$ & & & & & \\
\hline \multicolumn{8}{|l|}{ Individual signs } \\
\hline 1. Central cyanosis & 6 & 1 & $\mathbf{0 . 0 1 2}^{+}$ & 12.2 & 98.8 & 85.7 & 64.8 \\
\hline 2. Chest in-drawing & 41 & 61 & $0.314^{\#}$ & 83.7 & 23.8 & 40.2 & 70.4 \\
\hline 3. Crepitation & 20 & 23 & $0.158^{\#}$ & 40.8 & 71.2 & 46.5 & 66.3 \\
\hline 4. Grunting & 18 & 14 & $\mathbf{0 . 0 1 4 ^ { \# }}$ & 36.7 & 82.5 & 56.2 & 68.0 \\
\hline 5. Head nodding & 3 & 1 & $0.153^{+}$ & 6.1 & 98.8 & 75.0 & 63.2 \\
\hline 6. Inability to feed & 21 & 5 & $<\mathbf{0 . 0 0 1} \#$ & 42.9 & 93.8 & 80.8 & 72.8 \\
\hline 7. Lethargy & 13 & 2 & $<\mathbf{0 . 0 0 1}^{+}$ & 26.5 & 97.5 & 86.7 & 68.4 \\
\hline 8. Loss of consciousness & 12 & 2 & $<0.001+$ & 24.5 & 97.5 & 85.7 & 97.5 \\
\hline 9. Nasal flaring & 38 & 37 & $<0.001$ & 77.6 & 60.0 & 54.3 & 81.4 \\
\hline 10. Restlessness & 12 & 4 & $0.002^{+}$ & 24.5 & 95.0 & 75.0 & 67.3 \\
\hline 11. Tachypnoea & 47 & 74 & $0.702^{+}$ & 95.9 & 7.5 & 38.8 & 75.0 \\
\hline \multicolumn{8}{|l|}{ Combination of clinical signs } \\
\hline $\begin{array}{l}\text { 1. Central cyanosis \& } \\
\text { grunting. }\end{array}$ & 3 & 0 & $0.053^{+}$ & 6.1 & 100.0 & 100.0 & 63.5 \\
\hline $\begin{array}{l}\text { 2. Central cyanosis \&nasal } \\
\text { flaring }\end{array}$ & 5 & 1 & $0.029^{+}$ & 10.2 & 98.8 & 83.3 & 64.2 \\
\hline 3. Grunting \&nasal flaring & 14 & 9 & 0.017 & 28.6 & 88.8 & 60.9 & 67.0 \\
\hline $\begin{array}{l}\text { 4. Tachypnoea \&nasal } \\
\text { flaring }\end{array}$ & 36 & 30 & $<\mathbf{0 . 0 0 1}^{\#}$ & 73.5 & 62.5 & 54.5 & 79.4 \\
\hline
\end{tabular}

\# - Pearson chi-square applied; + - Fisher's Exact Test applied; PPV- Positive predictive value;

NPV - Negative predictive value

Table 4: Binary logistic regression model of the clinical signs as Predictors of hypoxaemia.

\begin{tabular}{llllll}
\hline Independent variables & \multirow{2}{*}{$\begin{array}{c}\text { Frequency } \\
\text { (N) }\end{array}$} & \multicolumn{4}{c}{ Outcome $=$ Hypoxaemia } \\
\cline { 3 - 6 } & 6 & 2.400 & 11.02 & $1.29-94.6$ & $\mathbf{0 . 0 2 9}$ \\
\hline 1. Central cyanosis & 18 & 1.007 & 2.73 & $1.21-6.21$ & $\mathbf{0 . 0 1 6}$ \\
2. Grunting & 21 & 2.420 & 11.25 & $3.87-32.72$ & $<\mathbf{0 . 0 0 1}$ \\
3. Inability to feed & 13 & 2.645 & 14.08 & $3.02-65.71$ & $\mathbf{0 . 0 0 1}$ \\
4. Lethargy & 12 & 2.583 & 12.65 & $2.69-59.43$ & $\mathbf{0 . 0 0 1}$ \\
5. Loss of consciousness & 38 & 1.645 & 5.18 & $2.31-11.60$ & $<\mathbf{0 . 0 0 1}$ \\
6. Nasal flaring & 12 & 1.818 & 6.16 & $1.86-20.42$ & $\mathbf{0 . 0 0 3}$ \\
7. Restlessness & 5 & 2.195 & 8.98 & $1.02-79.29$ & $\mathbf{0 . 0 4 8}$ \\
8.Cyanosis and nasal flaring & 14 & 1.149 & 3.16 & $1.25-7.99$ & $\mathbf{0 . 0 1 5}$ \\
9. Grunting and nasal flaring & 14 & 1.529 & 6.62 & $2.12-10.06$ & $<\mathbf{0 . 0 0 1}$ \\
10.Tachypnoea and nasal flaring & 36 & & &
\end{tabular}


Table 5: Hypoxaemia and outcome of the illness.

\begin{tabular}{|c|c|c|c|c|}
\hline & $\begin{array}{l}\text { Hypoxaemic } \\
\text { N=49 } \\
\mathrm{N}(\%) \\
\end{array}$ & $\begin{array}{l}\text { Non- } \\
\text { hypoxaemic } \\
\mathbf{N}=\mathbf{8 0} \\
\mathbf{N}(\%) \\
\end{array}$ & Test statistics & p-value \\
\hline $\begin{array}{l}\text { Days on admission } \\
=5 \text { days } \\
>5 \text { days }\end{array}$ & $\begin{array}{l}23(25.6) \\
26(66.7)\end{array}$ & $\begin{array}{l}67(74.4) \\
13(33.3)\end{array}$ & $X^{2}=19.522$ & $<0.001$ \\
\hline $\begin{array}{l}\text { Illness outcome } \\
\text { Discharge } \\
\text { DAMA } \\
\text { Death }\end{array}$ & $\begin{array}{l}36(31.9) \\
1(33.3) \\
12(92.3) \\
\end{array}$ & $\begin{array}{l}77(68.1) \\
2(66.7) \\
1(7.7) \\
\end{array}$ & $\mathrm{LR} \chi 2=19.009$ & $<0.001$ \\
\hline
\end{tabular}

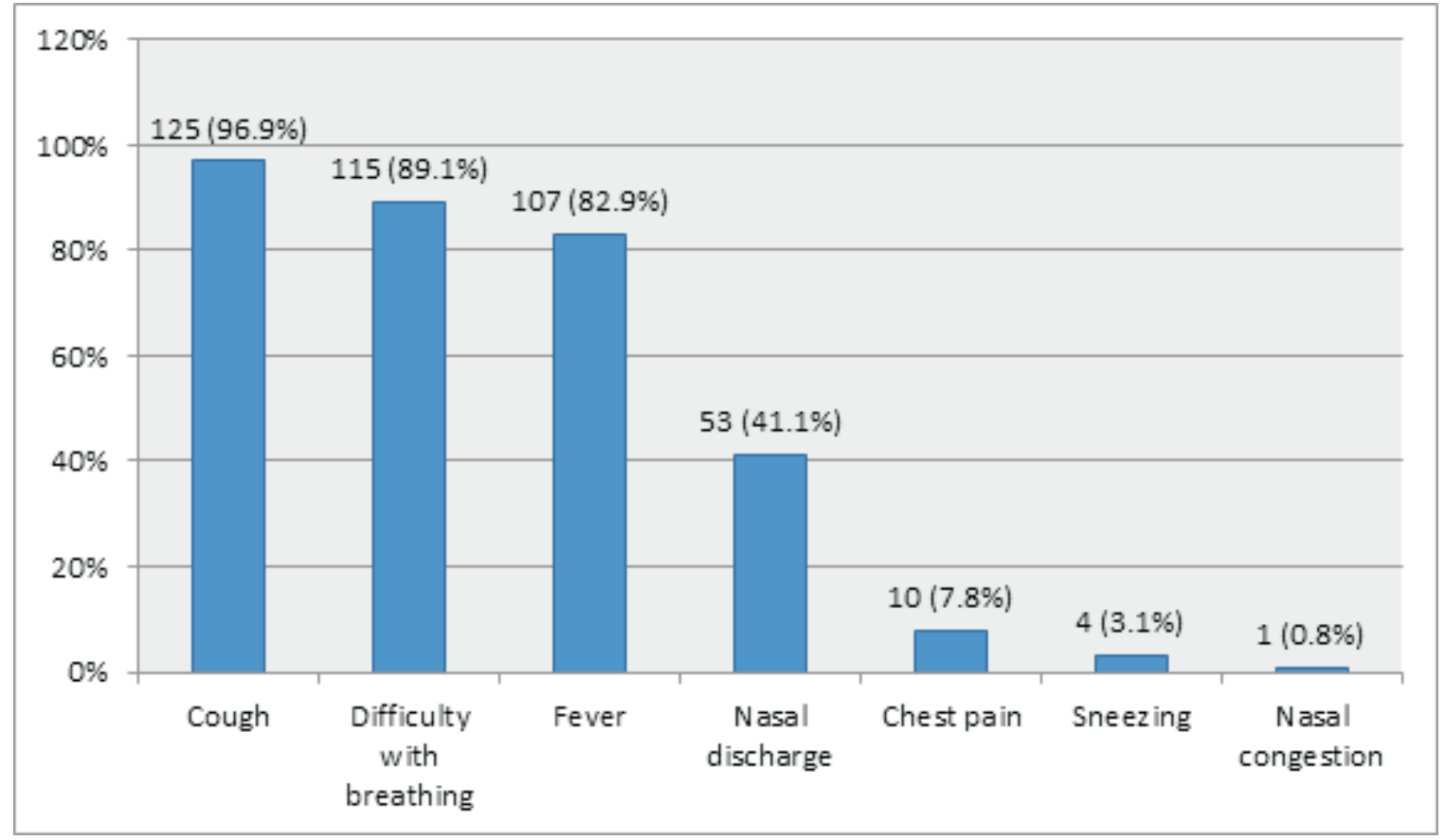

Figure 1: The respiratory symptoms in the subjects.

*Multiple symptoms present in some patients 


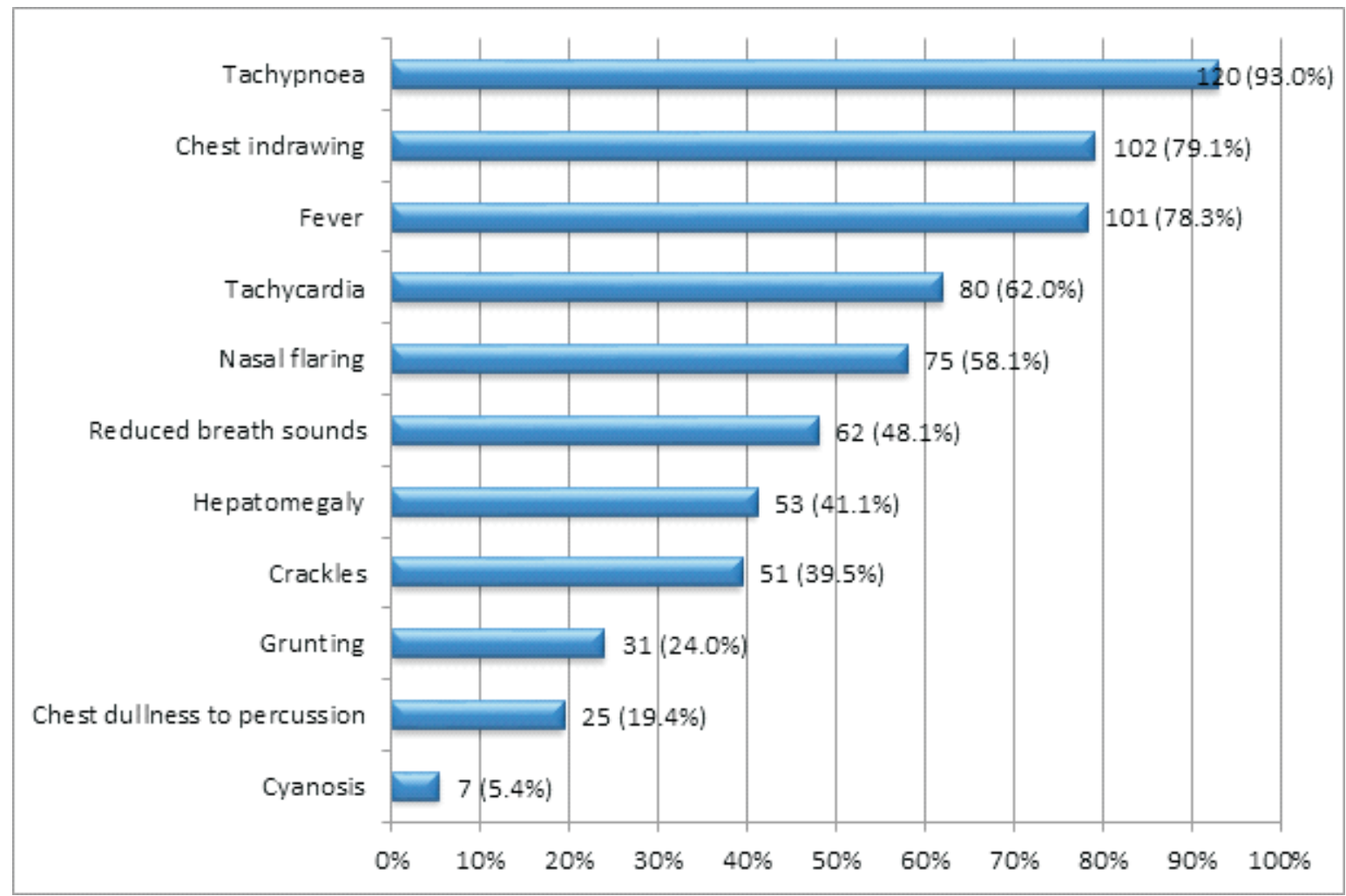

Figure 2: Clinical signs elicited in the subjects.

*Multiple signs present in some subjects 